\title{
Crude extract of hydatid laminated layer from Echinococcus granulosus cyst attenuates mucosal intestinal damage and inflammatory responses in Dextran Sulfate Sodium induced colitis in mice
}

Imene Soufli ${ }^{1}$, Ryma Toumi ${ }^{1}$, Hayet Rafa ${ }^{1}$, Manel Amri ${ }^{1}$, Moussa Labsi ${ }^{1}$, Lila Khelifi ${ }^{1}$, Ferdinando Nicoletti ${ }^{2}$ and Chafia Touil-Boukoffa ${ }^{*}$

\begin{abstract}
Background: Inflammatory bowel disease is an immunologically mediated disease. Notably, it is less common in countries where there is a greater risk of exposure to helminths. In our study, we examined the modulatory effect of the laminated layer extracted from the cyst wall of a helminth parasite, Echinococcus granulosus, on dextran sulfate sodium (DSS)-induced colitis in mice.
\end{abstract}

Methods: An acute colitis was induced in BALB/c mice using 2.5\% w/v DSS in drinking water. The crude extract of E. granulosus laminated layer was injected intraperitoneally daily, starting 3 days before colitis induction. The Disease Activity Index was monitored daily, colon length and weight were measured and histological scores were evaluated. Nitric oxide (NO) and cytokine levels (interferon $\gamma$ (IFN- $\gamma$ ), tumor necrosis factor a (TNF-a) and interleukin 10 (IL-10)) were assessed by enzyme-linked immunosorbent assay. In addition, the colonic expression of inducible nitric oxide synthase (iNOS) and nuclear factor-kB (NF-kB) was examined. Statistical analyses were performed by one-way analysis of variance and the survival rate was analyzed by the long rank test.

Results: Hydatid laminated layer pretreatment significantly improved the clinical symptoms and histological scores $\left.{ }^{* * *} p<0.01\right)$ observed during DSS-induced colitis and maintained mucus production by goblet cells. Furthermore, treatment with hydatid laminated layer caused a significant decrease in NO, IFN- $\left({ }^{* *} p<0.01\right)$ and TNF-a production $\left({ }^{*} p<0.05\right)$ and an increase in IL-10 production. These results were associated with localized downregulation of iNOS and NF-KB expression.

Conclusions: Our results demonstrate the potent anti-inflammatory effects of hydatid laminated layer. Furthermore, preventive treatment with the laminated layer played a beneficial role in maintaining the integrity of the intestinal mucosal barrier against DSS-induced injury.

Keywords: Inflammatory bowel disease (IBD), Experimental colitis, Nitric oxide (NO), Inducible nitric oxide synthase (iNOS), Nuclear factor-KB, Interferon (IFN)- $\gamma$, tumor necrosis factor (TNF)-a, helminth, hydatid laminated layer, Echinococcus granulosus

\footnotetext{
*Correspondence: touilboukoffa@yahoo.fr

'Department of Biology, Laboratory of Cellular and Molecular Biology, University of Sciences and Technology Houari Boumediene USTHB, Algiers, Algeria

Full list of author information is available at the end of the article
} 


\section{Background}

Inflammatory bowel disease (IBD), represented mainly by ulcerative colitis and Crohn's disease, is a chronic relapsing inflammatory condition that mainly affects the large and/or the small intestine. Its multi-factorial etiology remains poorly understood but it is widely accepted that IBD results from an uncontrolled mucosal immune response to intestinal microflora in genetically susceptible hosts [1,2]. Dysfunction of the mucosal immune response leads to infiltration of inflammatory cells into the gut mucosa and concomitant production of large amounts of proinflammatory cytokines including interleukin $1 \beta$ (IL-1ß), IL-6, interferon $\gamma$ (IFN- $\gamma)$, tumor necrosis factor $\alpha$ (TNF- $\alpha$ ) and nitric oxide (NO) [3]. The pro-inflammatory cytokines IFN- $\gamma$ and TNF- $\alpha$ are important inducers of inducible nitric oxide synthase (iNOS) expression in macrophages, intestinal epithelial cells and other cells [4].

Many authors have reported that high expression of iNOS, a mediator of elevated NO production in inflamed colonic mucosa, is strongly associated with the mucosal lesions observed in both human IBD pathogenesis and experimental colitis [4-9]. Moreover, the expression of proinflammatory cytokines (IL-1ß, TNF- $\alpha$, IL-6) and iNOS are transcriptionally regulated by the transcription factor nuclear factor (NF)- $\mathrm{kB}$ [4]. In addition to these immunological factors, it has been reported that environmental factors strongly influence the onset of IBD. Thus, IBD was initially described as pathologies affecting mainly the industrialized countries. Currently, these observations are no longer accurate considering the increasing occurrence of IBD in developing countries. These observations support the "hygiene hypothesis", which states that childhood exposure to helminths reduces the risk of developing IBD [10-12]. On the basis of these observations, many studies have focused on the protective and therapeutic effects of different helminth species in experimental colitis. Indeed, infection of mice with nematode helminths including Heligmosomoides polygyrus, Trichinella spiralis, the trematode Schistosoma mansoni and the cestode Hymenolepis diminuta demonstrated a protective effect against colitis in various animal models [13-18]. Furthermore, these studies have been extended to patients with IBD. Clinical trials demonstrated that administration of eggs from the porcine whipworm, Trichuris suis, to patients with IBD attenuated the excessive intestinal inflammation [19-21].

Echinococcus granulosus is a helminth that causes a cystic hydatid disease. Human cysts of E. granulosus are mainly located in the lung or the liver [22]. The cyst consists of a fluidfilled vesicle, containing two layers, a germinal layer and an outer acellular laminated layer (LL). The LL of E. granulosus is composed mainly of carbohydrates, proteins and lipids [23]. It appears to play two essential roles, as a mechanical barrier and an immunological barrier against the host immune defense. In fact, the survival and persistence of the parasite in the host involves evasion strategies that may be mediated by the LL-induced inhibition of NO production [24-26]. In our study, we investigated the potential protective effect of the hydatid LL of E. granulosus in dextran sulfate sodium (DSS)-induced experimental colitis. Here, we report that pretreatment of colitic mice with the crude extract of LL significantly reduced the severity of colitis, both macroscopically and histologically. Interestingly, this observation correlated with a significant decrease in NO production and proinflammatory cytokine (TNF- $\alpha$, IFN- $\gamma$ ) secretion and importantly an increase in the systemic IL-10 level. Concomitantly, localized attenuation of iNOS and NF- $\mathrm{kB}$ expression was evident in LL-pretreated mice.

\section{Methods}

\section{Mice}

Female BALB/c mice (8 weeks old) were purchased from the Pasteur Institute (Algiers, Algeria). These mice were acclimated for 1 week before the start of experiments and kept under normal conditions with a $12 \mathrm{~h}$ dark/light cycle with ad libitum access to food and water. Mice ranging in weight from $20-22 \mathrm{~g}$ were divided into four groups ( $n=6-10$ mice per group) as per Figure 1. This study was approved by the ethics committee of the national agency of research development in health (ANDRS).

\section{Initiation of acute DSS-induced colitis in mice}

Mice were treated with 2.5\% (w/v) DSS (MW 36 000-44 000; TdB Consultancy, Sweden) in their drinking water ad libitum for 7 consecutive days as described by Okayasu et al. [27] to induce acute colitis. Mice were weighed every day during the experiment and their clinical status, including weight loss, stool consistency and/or diarrhea and presence of blood in stool, was monitored. The Disease Activity Index (DAI) was determined as described previously $[18,28]$. Briefly, a score from 0 to 4 was given for each parameter with a maximum DAI score of 12, as follows: score $0=$ no weight loss, normal stool, no blood; score $1=1-3 \%$ weight loss; score $2=3-6 \%$ weight loss, loose stool, presence of blood in stool; score 3 = 6-9\% weight loss; score $4=>9 \%$ weight loss, diarrhea, presence of fresh blood around the anus with extensive blood in the stool.

\section{Preparation of the crude extract of hydatid laminated layer}

Hydatid cysts from human lungs were obtained from the Department of Thoracic Surgery, Mustapha Pacha Hospital (Algiers, Algeria). Each patient gave written informed consent for the study as required by the ethics committee 


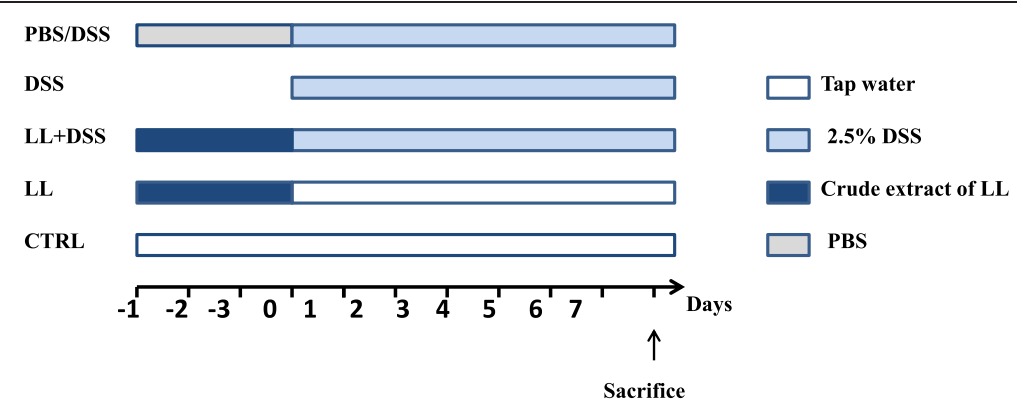

Figure 1 Experimental plan. Mice were randomly divided into five experimental groups ( $n=6-10$ per group). CTRL group received drinking water only. DSS group received 2.5\% (w/v) DSS in their drinking water ad libitum for 7 days to induce acute colitis. LL/DSS group were injected daily with $200 \mu \mathrm{L}$ LL by intra-peritoneal injection starting 3 days before and then concomitantly with DSS administration. LL group were injected daily with $200 \mu \mathrm{l}$ of LL by intra-peritoneal injection during the 10 days. PBS/DSS group were injected daily with $200 \mu$ l of PBS by intra-peritoneal injection starting 3 days before and then concomitantly with DSS administration. The arrow shows the day when mice were euthanized.

of the ANDRS which approved the study. The crude extract of LL was prepared as described previously by Steers et al. [24]. Briefly, the hydatid cyst fluid was aseptically removed by needle aspiration. Then, the hydatid cyst membrane was washed several times in phosphate-buffered saline (PBS) supplemented with 300 UI penicillin and $0.3 \mathrm{mg} / \mathrm{ml}$ streptomycin and frozen overnight to help the removal of the LL. The latter was removed and sonicated in PBS containing a cocktail of protease inhibitors (Invitrogen, Life Technologies, Carlsbad, CA, USA), for $10 \mathrm{~s}$ per min on ice until a particulate solution was obtained. Endotoxin contamination was removed using endotoxin removing resin (Pierce Biotechnology, ThermoFisher Scientific, Waltham, MA, USA). The absence of lipopolysaccharide in the crude extract was verified using the Endosafe Limulus Amebocyte Lysate test (Charles River Laboratories, Wilmington, MA, USA).

$\mathrm{BALB} / \mathrm{c}$ mice were injected daily with $200 \mu \mathrm{l}$ crude extract of LL by intraperitoneal injection, starting 3 days before and then concomitantly with DSS administration.

\section{Plasma collection}

Mice were anesthetized with chloroform, and blood was collected via cardiac puncture. Blood was centrifuged to isolate plasma, which was kept at- $20^{\circ} \mathrm{C}$ until use.

\section{Preparation of peritoneal macrophages and cell culture}

Macrophages were obtained by peritoneal lavage of mice using $5 \mathrm{ml}$ of sterile PBS ( $\mathrm{pH}=7.4$ ). Cellular suspensions were washed three times with sterile PBS by centrifugation at $2800 \mathrm{rpm}$ for $5 \mathrm{~min}$, and then the pellets resuspended in Dulbecco's modified Eagle's medium (DMEM) supplemented with $10 \%$ heat inactivated fetal bovine serum, $100 \mathrm{U} / \mathrm{ml}$ penicillin, $0.1 \mathrm{mg} / \mathrm{ml}$ streptomycin and $20 \mathrm{mM}$ L-glutamine. Cells were cultured at a density of $4 \times 10^{5}$ cells/well in 24-well tissue culture plates. After 2 hours, wells were washed using sterile PBS to remove non-adherent cells. Peritoneal macrophages (pM $\Phi)$ were incubated in complete DMEM at $37^{\circ} \mathrm{C}$ and $5 \% \mathrm{CO}_{2}$ for $24 \mathrm{~h}$. The cells used for all experiments were cultured in triplicate. After $24 \mathrm{~h}$, the supernatants were removed and stored at $-20^{\circ} \mathrm{C}$ for nitrite concentration measurement.

\section{Nitrite concentration measurement}

The Griess reaction was used to determine nitrite levels as an indicator of NO production, in all culture supernatants and plasma, as described previously [29]. Briefly, $100 \mu \mathrm{l}$ of each sample was mixed with $50 \mu \mathrm{l}$ of Griess reagent (5\% sulfanilamide, $0.5 \%$ napthylethylenediamine dihydrochloride, $20 \% \mathrm{HCl}$ ). Samples were incubated at room temperature for $20 \mathrm{~min}$ and the absorbance read at $543 \mathrm{~nm}$ by spectrophotometer. The nitrite concentration was determined using a standard curve constructed with sodium nitrite $\left(\mathrm{NaNO}_{2} ; 0-200 \mu \mathrm{mol} / \mathrm{ml}\right)$.

\section{Measurement of systemic cytokine levels}

Systemic levels of IFN- $\gamma$, TNF- $\alpha$ and IL-10 were determined in the plasma of mice using commercial enzymelinked immunosorbent assay (ELISA) kits according to the manufacturer's instructions (Invitrogen).

\section{Assessment of colonic damage}

After euthanasia, the colon was isolated and carefully cleaned of mesentery tissue, vessels and fat, and the length measured. A $4 \mathrm{~cm}$ segment of the distal colon was removed and weighed after rinsing the lumen with PBS. For the histological examination, $1 \mathrm{~cm}$ segments from the distal colon were fixed in $10 \%$ formalin, mounted in paraffin blocks and cut into 4- $\mu \mathrm{m}$-thick sections. The sections were stained with hematoxylin and eosin (H \& E) to study histological changes and with the Alcian blue method to evaluate mucus secretion by goblet cells. Sections were assessed in a blinded fashion as previously described $[18,30]$. Briefly, a combined score of inflammatory cell infiltration and tissue damage was determined as follows. 
Cell infiltration: score 0 , occasional inflammatory cells in the lamina propria; score 1, increased infiltrate in the lamina propria predominantly at the base of crypts; score 2, confluence of inflammatory infiltrate extending into the mucosa; score 3 , transmural extension of infiltrate.

Tissue damage: score 0 , no mucosal damage; score 1 , $<50 \%$ loss of crypts in large areas; score 2, $\geq 50 \%$ loss of crypts in large areas, epithelium intact; score 3, total loss of crypts in large areas and epithelium loss.

\section{Investigation of NF-кB and iNOS expression by immunofluorescence}

An immunofluorescence study of NF- $\mathrm{kB}$ and iNOS expression was performed on formalin-fixed, paraffinembedded samples. Sections of 3 - $\mu$ m-thick tissue were deparaffinized using xylene solvent, and rehydrated through a graded series of ethanol. The sections were then subjected to antigen retrieval in citrate buffer at $\mathrm{pH} 6.0,95^{\circ} \mathrm{C}$ for $45 \mathrm{~min}$. Sections were blocked for $2 \mathrm{~h}$ with $5 \%$ skim milk in PBS, then incubated with rabbit monoclonal antibodies against mouse NF-kB p65 subunit and iNOS (Santa Cruz Biotechnology, Dallas, TX, USA; diluted 1:100) overnight at $4^{\circ} \mathrm{C}$. Finally, sections were labelled with anti-rabbit IgG-FITC (Life Technologies, diluted 1:1000) for 1 hour. Sections were washed three times with PBS between each step. Slides were covered with Kaiser's glycerin-PBS and examined using a Zeiss inverted fluorescence microscope (Zeiss, Oberkochen, Germany). Pictures were taken using a digital camera at $\times$ 40 magnification.

\section{Statistical analysis}

All data are expressed as the means \pm standard error of the mean (SEM). Statistical analyses were performed by oneway analysis of variance to compare both time (days of DSS) and treatment effects. Probability values of $p<0.05$ were considered to be statistically significant.

\section{Results}

Preventive treatment with hydatid LL ameliorates clinical symptoms of DSS-induced colitis

After administration of $2.5 \%$ DSS to mice in their drinking water, all animals developed symptoms of colitis including progressive weight loss, diarrhea and gross rectal bleeding from days 4 to 5 after the start of DSS administration. These symptoms were more marked at the end of the experimental period, when animals showed multiple clinical signs of severe disease, including marked weight loss and moribund state. Of the 10 mice in the DSS group, three died between days 5 and 7 (Figure 2). However, pretreatment with hydatid laminated layer (LL/DSS) significantly reduced the clinical score (DAI) in comparison with the DSS group. Furthermore, no moribund symptoms or mortality occurred in the LL/ DSS group (Figure 2).

\section{Pretreatment with hydatid LL attenuates histological alterations in DSS-induced colitis}

Shortening of the colon is used as a marker of inflammation in the DSS-induced colitis model. In the DSSalone group the length of the colon was significantly shortened $\left(4.6 \pm 0.40 \mathrm{~cm},{ }^{* * * *} p<0.0001\right)$ compared with the control untreated group $(7.95 \pm 0.76 \mathrm{~cm})$, whereas in the DSS/LL group the pretreatment with LL prevented the colonic shortening $(6.3 \pm 0.58 \mathrm{~cm}$, *** $p<$ 0.001 , Figure $3 \mathrm{~A}$ and $\mathrm{B})$. No significant difference was observed between the LL alone group and the untreated control group (Figure 3A).

The histological analysis of the distal colon of DSS treated mice revealed marked mucosal damage, characterized by an intense inflammatory cell infiltrate extending throughout the mucosa and submucosa, crypt destruction, total depletion of goblet cells and mucosa erosion (Figure 3E). However, in the LL/DSS group, LL pretreatment significantly decreased the histological score compared with the DSS group (*** $p<0.001$, Figure 3D). The tissue alterations were also markedly reduced in LL/DSS group, with less cellular infiltration into the mucosa, more intact epithelium structure and normal crypts observed in the majority of mice of this group (Figure 3E). The untreated control group showed normal colonic mucosa and submucosa (Figure 3E) and mice from LL alone group displayed the same histological structure.

Furthermore, histological analysis using Alcian blue staining showed enhanced mucus production in LL/DSS mice compared with the DSS group, where a total depletion of goblet cells was observed (Figure 4A). Higher numbers of goblet cells associated with mucus secretion were found in the LL/DSS group in comparison with the DSS group $(p<0.001$, Figure 4 A, B). The mice from the LL alone group displayed the same structure observed in control mice, with numerous goblet cells accompanied by mucus secretion observed in both these groups (Figure 4).

\section{Pretreatment with hydatid LL reduces systemic levels of NO in DSS-induced colitis}

$\mathrm{NO}$ is an important mediator of immune and inflammatory responses. It has been shown previously that $\mathrm{NO}$ is highly implicated in intestinal inflammation during IBD and experimental colitis [4-9]. In our current study, we focused our attention on investigating the effect of the crude extract of hydatid LL on NO production in DSSinduced colitis in mice.

NO measurement in the plasma of mice showed high systemic levels of $\mathrm{NO}$ in mice from the DSS group 

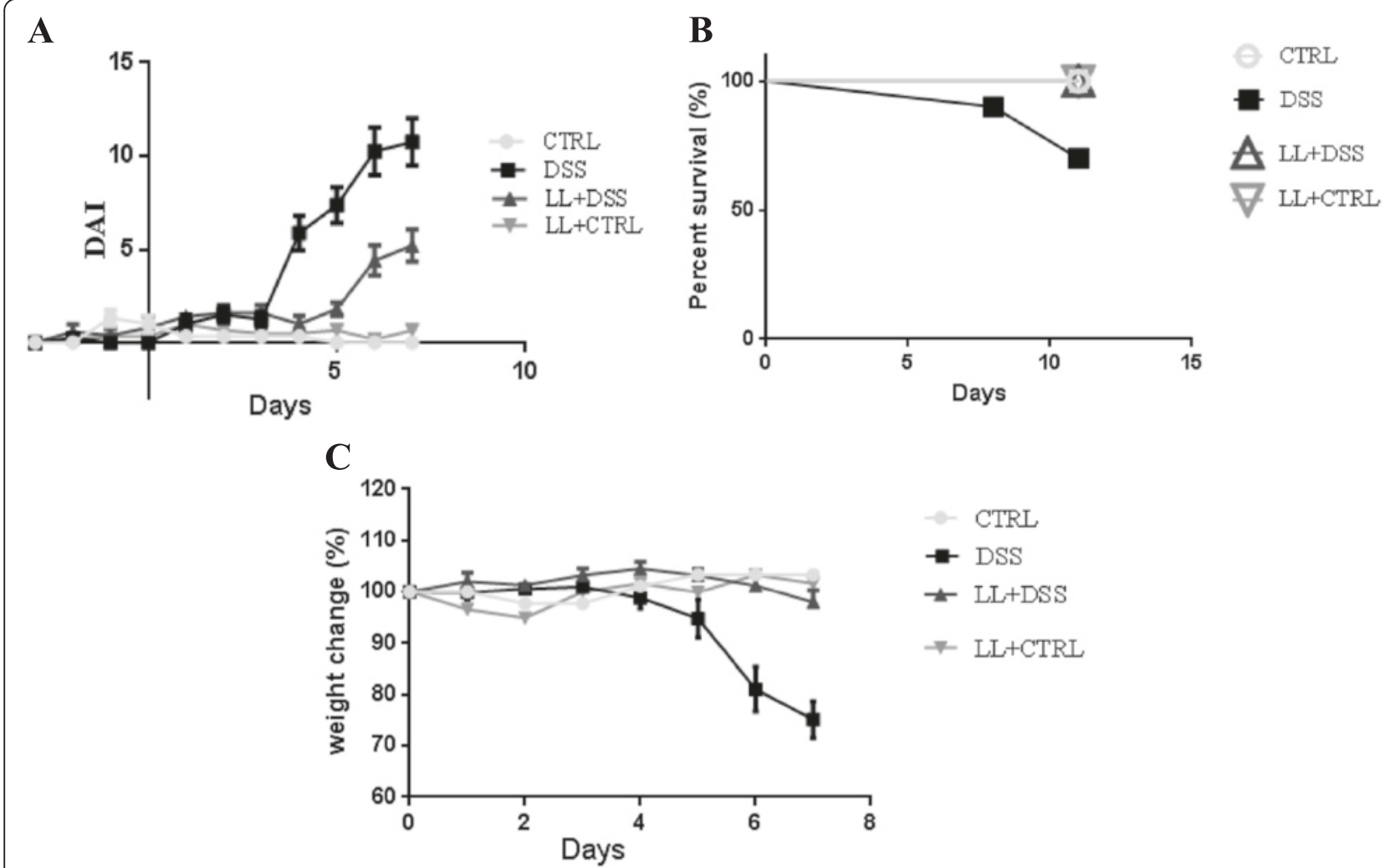

Figure 2 Pretreatment with hydatid ameliorates clinical symptoms of DSS-induced colitis. BALB/C mice were pretreated with the crude extract of LL starting 3 days before and then concomitantly with DSS administration. A, Weight loss, stool consistency, and fecal blood were scored to provide the DAI for each group. B, Survival rate of mice during the experiment. C, Percent change from original body weight in all groups. Data are shown for six to ten mice per group.

compared with control group $(10.07 \pm 2.27 \mathrm{~cm}$ versus $\left.4.40 \pm 1.48 \mathrm{~cm},{ }^{* * * *} p<0.001\right)$. However, pretreatment of mice with hydatid LL caused a significant decrease in systemic NO levels in comparison with mice treated with DSS alone (**:* $p<0.001$, Figure 5A). Moreover, there was no significant difference in $\mathrm{NO}$ levels in plasma of mice from the LL/DSS group and the untreated control group ( $p>0.05$, Figure 5A).

\section{Crude extract of hydatid LL reduces nitrite level in peritoneal macrophage cultures}

The nitrite level produced by cultured $\mathrm{pM} \Phi$ was measured. Nitrite production by cultures of $\mathrm{pM} \Phi$ obtained from colitic mice was significantly increased compared with $\mathrm{pM} \Phi$ from untreated control mice ${ }^{* * * * *} p<0.0001$, Figure 5B). Interestingly, NO concentration in $\mathrm{pM} \Phi$ supernatants was lower from hydatid LL pretreated mice, compared with all other experimental groups ${ }^{* * * * * *} p<$ 0.0001 DSS group versus LL/DSS group, ${ }^{* * *} p<0.01 \mathrm{LL} /$ DSS group versus untreated control group). Conversely, animals given hydatid LL without DSS consumption showed no difference in nitrite levels in comparison with the control group (Figure 5B).

\section{Changes in cytokine levels in vivo}

To analyze the effect of the hydatid LL on cytokine production in vivo during DSS-induced colitis, we measured the levels of proinflammatory cytokines (TNF- $\alpha$, IFN- $\gamma$ ) and the immunoregulatory cytokine IL-10 by ELISA in plasma from mice (Figure 6). Systemic IFN- $\gamma$ and TNF- $\alpha$ levels were markedly increased in the DSS group in comparison with controls $(p<0.01)$. Hydatid LL pretreatment significantly attenuated both IFN- $\gamma$ and TNF- $\alpha$ expression compared with mice treated with DSS alone $(* * 0<0.01$, $* p<0.05$ respectively). However, treatment of control mice with LL alone also induced an increase in plasma IFN- $\gamma$ and TNF- $\alpha$ level, although without any significant effect on overall health compared with the control group (Figure 6). The systemic levels of IL-10 were increased in the LL/DSS group in comparison with the DSS group, although no statistically significant differences were observed among the groups (Figure 6C).

Down-regulation of iNOS and NF-KB expression in colonic tissue of mice pretreated with crude extract of hydatid LL High expression of iNOS is considered the most important source of elevated nitrite levels in experimental colitis and in patients with IBD [4-7]. The expression of iNOS is 


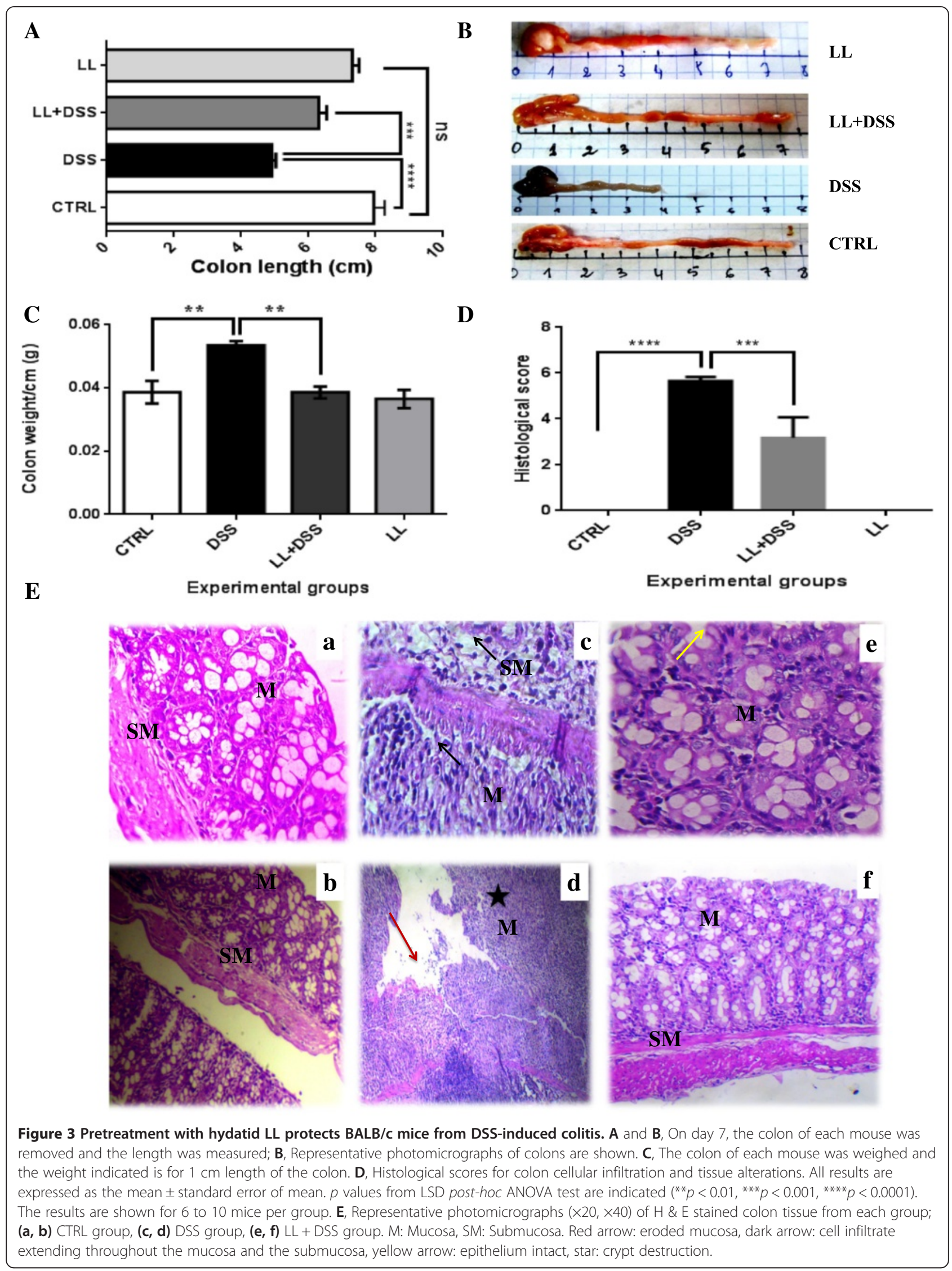


$\mathbf{A}$
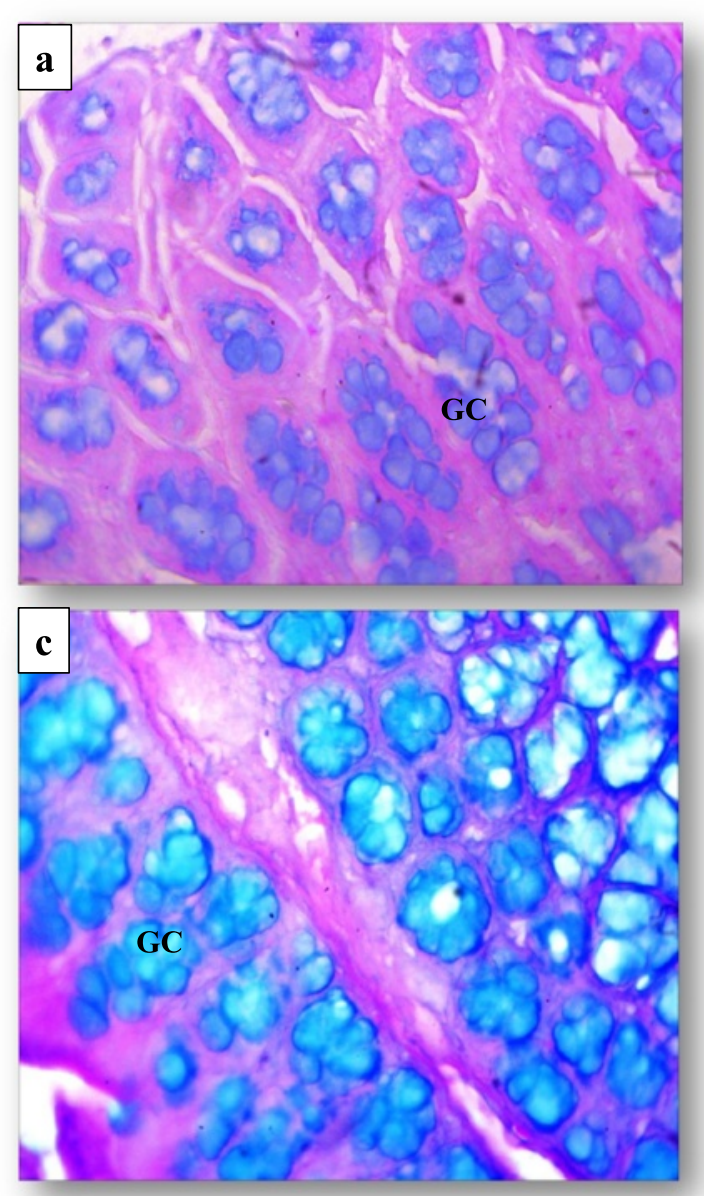

b
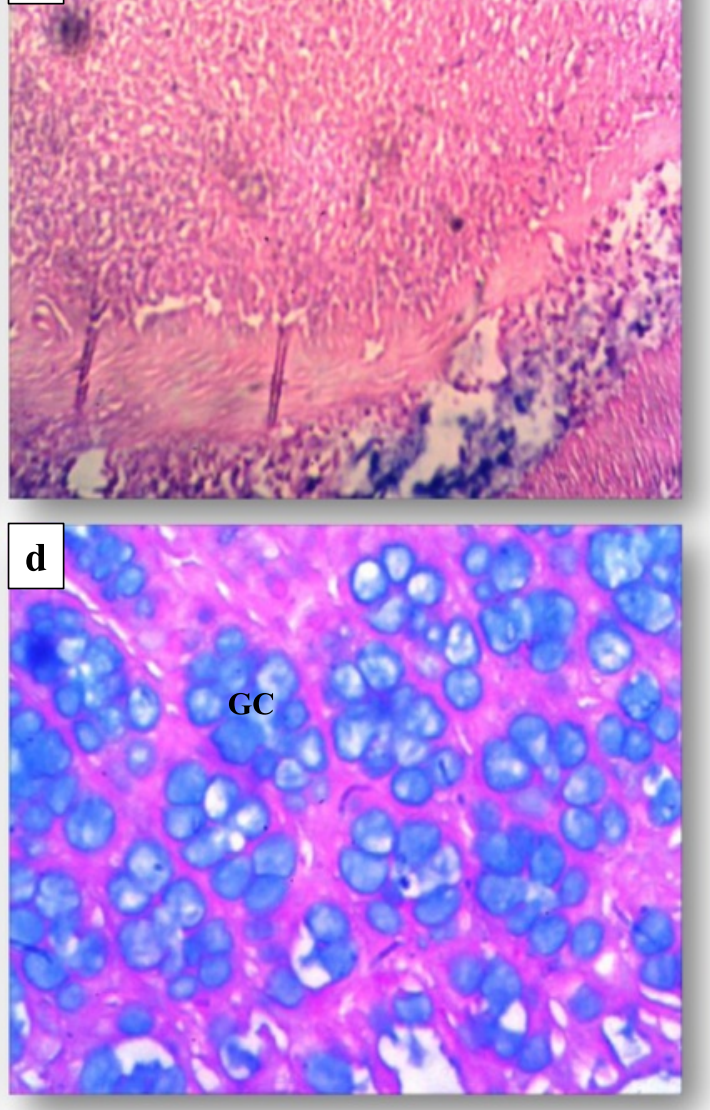

B

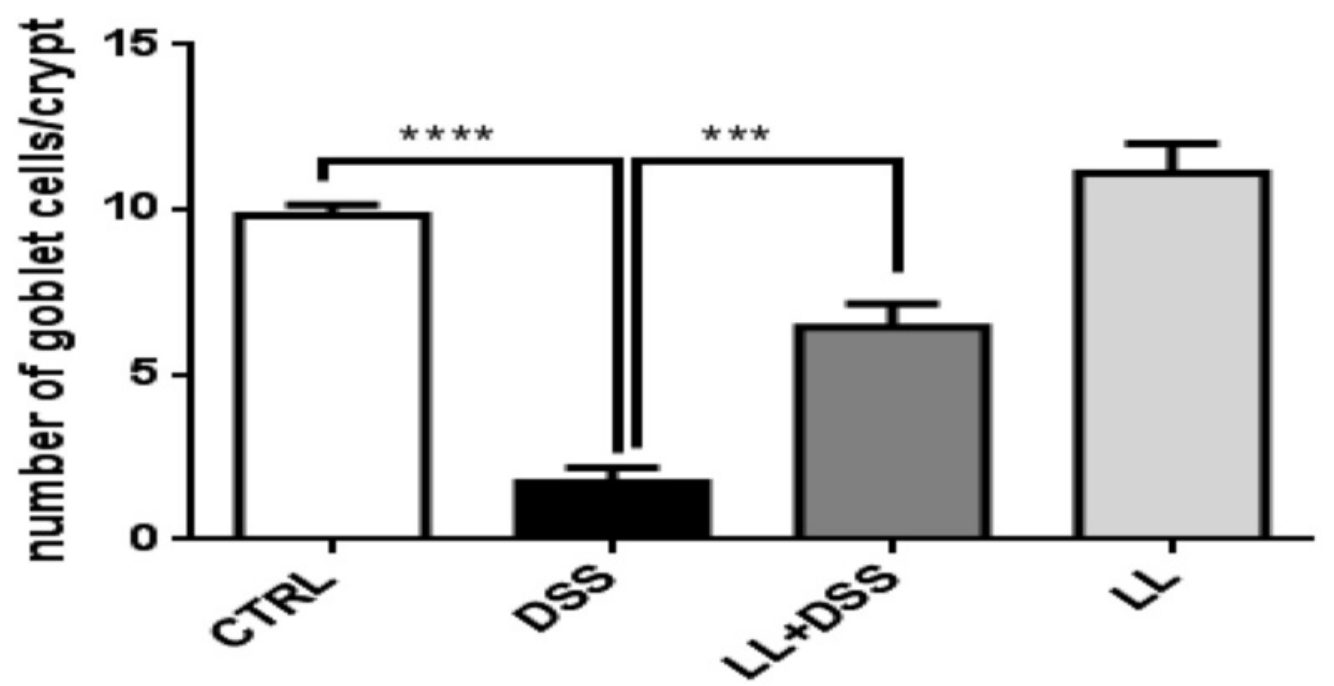

Experimental groups

Figure 4 (See legend on next page.) 
(See figure on previous page.)

Figure 4 Pretreatment with hydatid LL protects colonic goblet cells in DSS-induced colitis. A, Representative photomicrographs of Alcian blue stained colonic tissue. (a) CTRL group: normal crypts and important mucus secretion, (b) DSS group: total depletion of goblet cells accompanied by the absence of mucus, (c) LL+DSS group: normal crypts and secretion of mucus by the goblet cells. (d) LL group: normal crypts, presence of a number of goblet cells secreting mucus. B, Changes in goblet cells number. All results are expressed as the mean \pm standard error of the mean. $p$ values from LSD post-hoc ANOVA test are indicated ( $\left.{ }^{* *} p<0.001,{ }^{* * *} p<0.0001\right)$. GC: Goblet Cells.

transcriptionally regulated by NF- $\mathrm{BB}$. Therefore, we examined the effect of crude extract of hydatid LL on iNOS and NF- $\mathrm{KB}$ expression in DSS-induced colitis in mice. Colon tissue sections were tested for the expression of iNOS and NF- $\mathrm{kB}$ by immunofluorescence using antiiNOS and anti-NF-kB p65 subunit antibodies. The expression of both NF-kB and iNOS was markedly increased in the colonic mucosa of DSS treated mice in comparison with the untreated control group. This increase in expression in colonic mucosa was significantly attenuated by LL treatment (Figure 7).

\section{Discussion}

IBD is characterized by disruption of the intestinal microbiota that leads to an excessive inflammatory response in the gut. Currently, modulation of intestinal inflammation using helminths is being explored as a promising prophylactic and therapeutic approach for IBD. Several experimental studies using different animal models of colitis have shown the ability of parasitic worms to attenuate intestinal inflammation. Furthermore, intestinal parasitic worms such as T. suis have been shown to have a therapeutic effect in patients with ulcerative colitis and Crohn's disease [19-21]. The data presented here demonstrate that the pretreatment of mice with hydatid LL extracted from the cyst of the cestode parasite E. granulosus attenuates inflammation in a DSS-induced colitis model in mice.

The oral administration of $2.5 \%$ DSS in mice causes acute colitis. Animals from this group showed a variety of clinical symptoms of IBD including diarrhea, bloody stool and weight loss. A Disease Activity Index score was used as a reliable tool to assess the extent of the gastrointestinal disease in the DSS-induced experimental colitis. At the end of the experimental period, the clinical symptoms were more pronounced. Our observations are in agreement with those reported in other studies using the DSS-induced colitis model $[27,28]$. However, pretreatment of mice with hydatid LL significantly improved the clinical score, suggesting a protective effect of hydatid LL in this model of colitis. The histological scores indicate that pretreatment of mice with LL prevented mucosal damage characterized by loss of crypt glands and epithelium destruction and inhibited colon shortening as observed in the DSS-alone group. Moreover, a histological study using Alcian blue staining showed

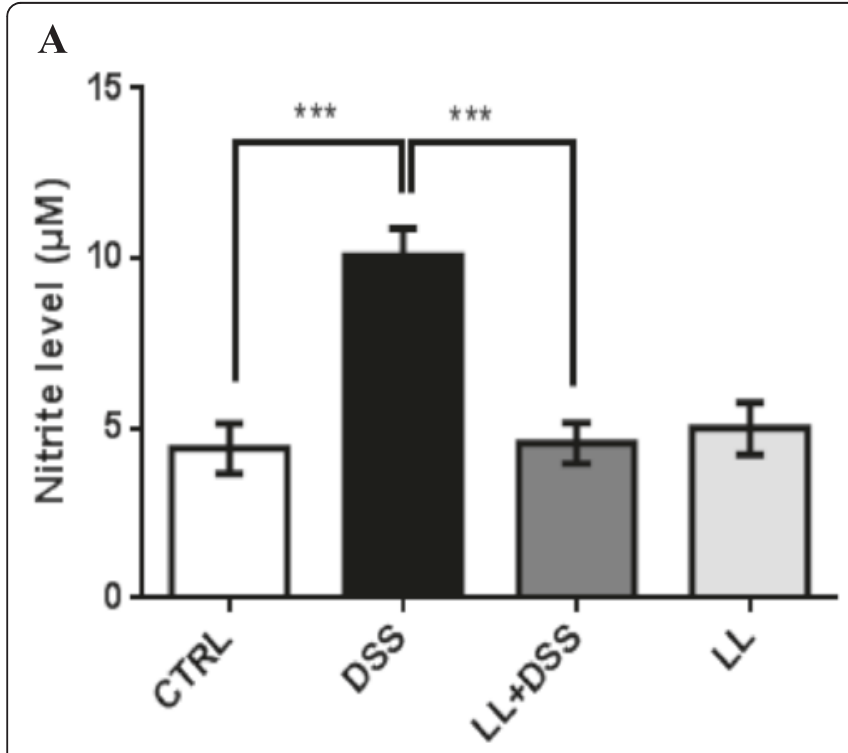

Experimental groups

\section{B}

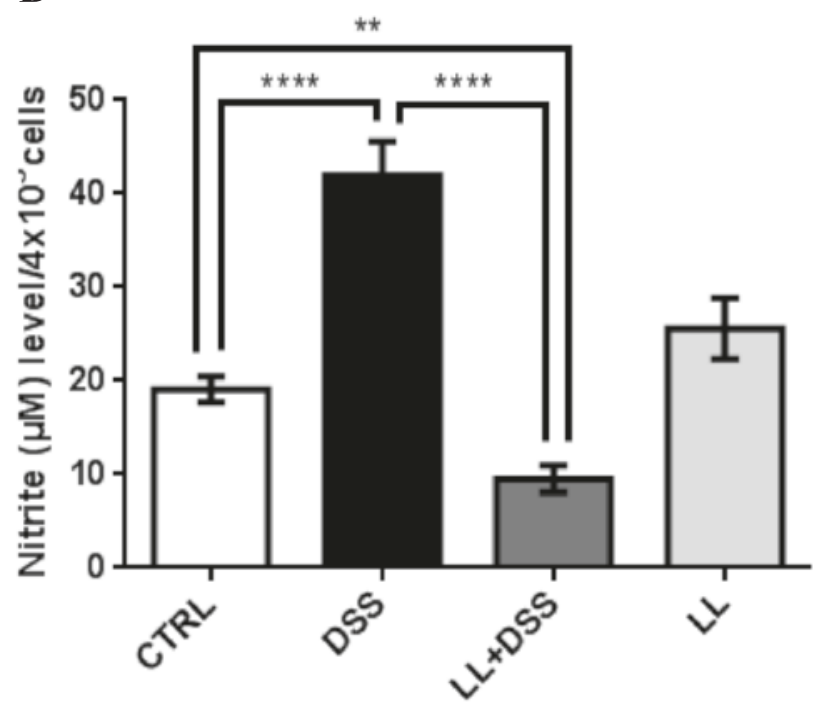

Experimental groups

Figure 5 LL pre-treatment reduces the production of nitric oxide in plasma (A) in DSS-induced colitis in BALB/C mice and in the supernatant of peritoneal macrophage cultures (B). All results are expressed as the means \pm SEM for 5 to 10 mice per group. $P$ values from LSD post-hoc ANOVA test are indicated $\left({ }^{* *} p<0.001,{ }^{* * *} p<0.0001\right)$. 


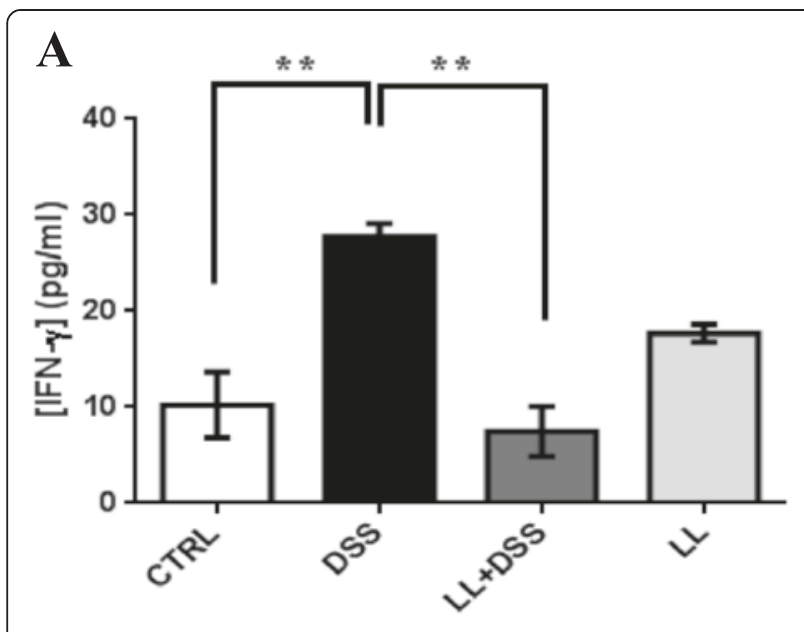

Experimental groups

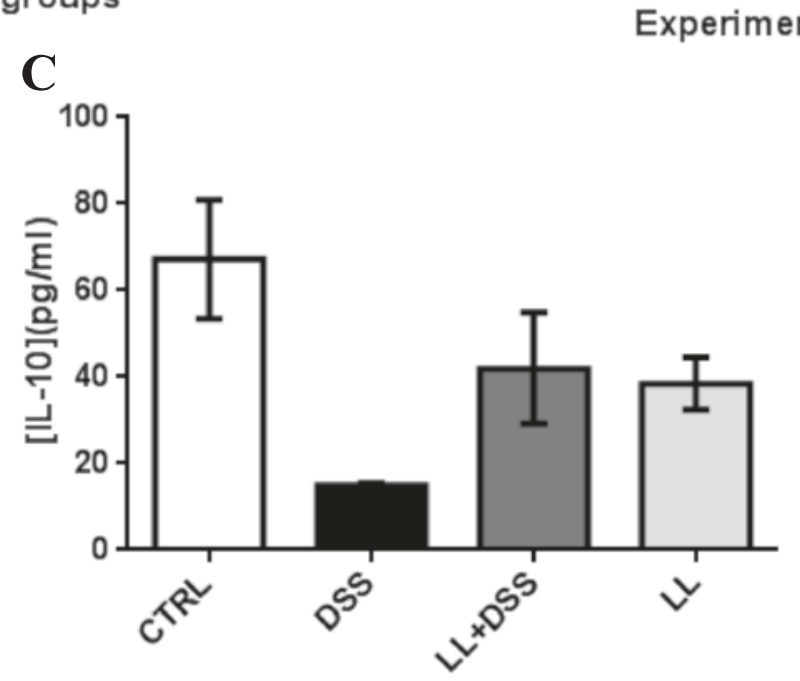

Experimental groups

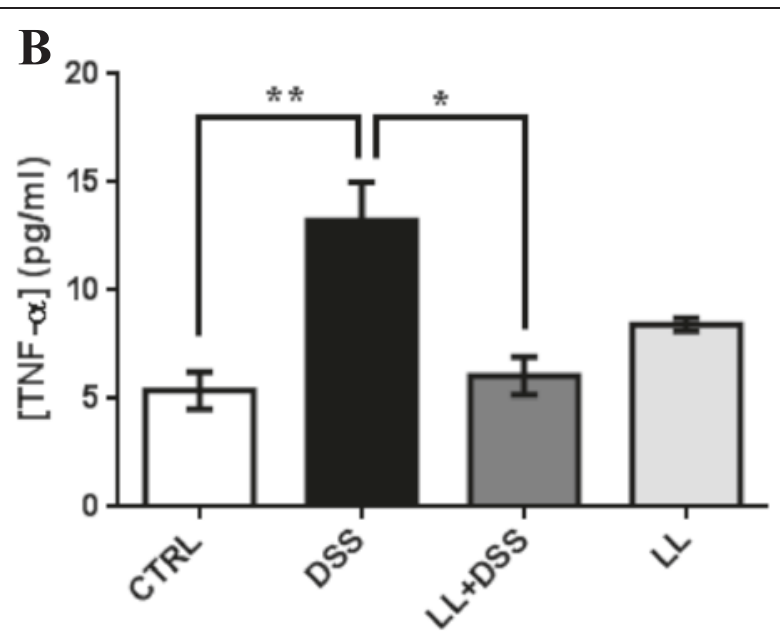

Experimental groups

Figure 6 Effect of crude extract of LL on cytokines in DSS-induced colitis. IFN- $\gamma(\mathbf{A})$, TNF- $a(\mathbf{B})$ and IL-10 (C) concentration in the plasma of mice from all groups. LL-pretreatment reduces the systemic levels of IFN- $\gamma$ and TNF-a and increased IL-10 systemic levels. All results are expressed as the mean \pm standard error of the mean. $p$ values from LSD post-hoc ANOVA test are indicated $\left({ }^{*} p<0.05,{ }^{* *} p<0.01\right)$. Abbreviations: IFN- $\gamma$, interferon- $\gamma_{\text {; TNF- }}$, tumor necrosis factor $a ;$ IL-10, interleukin 10.

regular mucosal structure with a number of goblet cells secreting mucus in the LL/DSS group, in stark contrast to the DSS treated mice. This observation suggests that LL pretreatment may protect mice from DSS-induced colitis by promoting mucus secretion.

IBD and DSS induced colitis are characterized by elevated levels of proinflammatory cytokines including IFN- $\gamma$, TNF- $\alpha$ and IL- 6 , and also increased NO production $[7,8]$, which contribute to the destruction of the epithelium, ulceration of the intestinal mucosa, erosion and infiltration of inflammatory cells [27,30,31]. We focused our attention on the effect of LL pretreatment on NO production and TNF- $\alpha$, IFN- $\gamma$ secretion knowing that these cytokines are potent inducers of iNOS expression $[4,32]$. Our data demonstrate an increase in NO levels both in plasma and macrophage culture supernatants of mice from the DSS group. Our results are in line with previous studies showing that intestinal inflammation observed in IBD and DSS-induced colitis is associated with prolonged iNOS activation and increased NO production [4,6,32]. In fact, NO contributes to the perpetuation of inflammation, causing increased tissue damage [33].

Many authors have reported the synergistic effect of IFN- $\gamma /$ TNF- $\alpha$ on iNOS induction through NF- $\alpha B$ activation $[34,35]$. Notably, NF- $k B$ activity is enhanced in the intestinal mucosa of both patients with IBD and the DSS-induced colitis model $[4,36]$. In our study, we reported that an elevated level of NO was associated with an increased systemic level of IFN- $\gamma$ and TNF- $\alpha$, and over expression of iNOS and NF- $\mathrm{kB}$ in colonic tissue. 


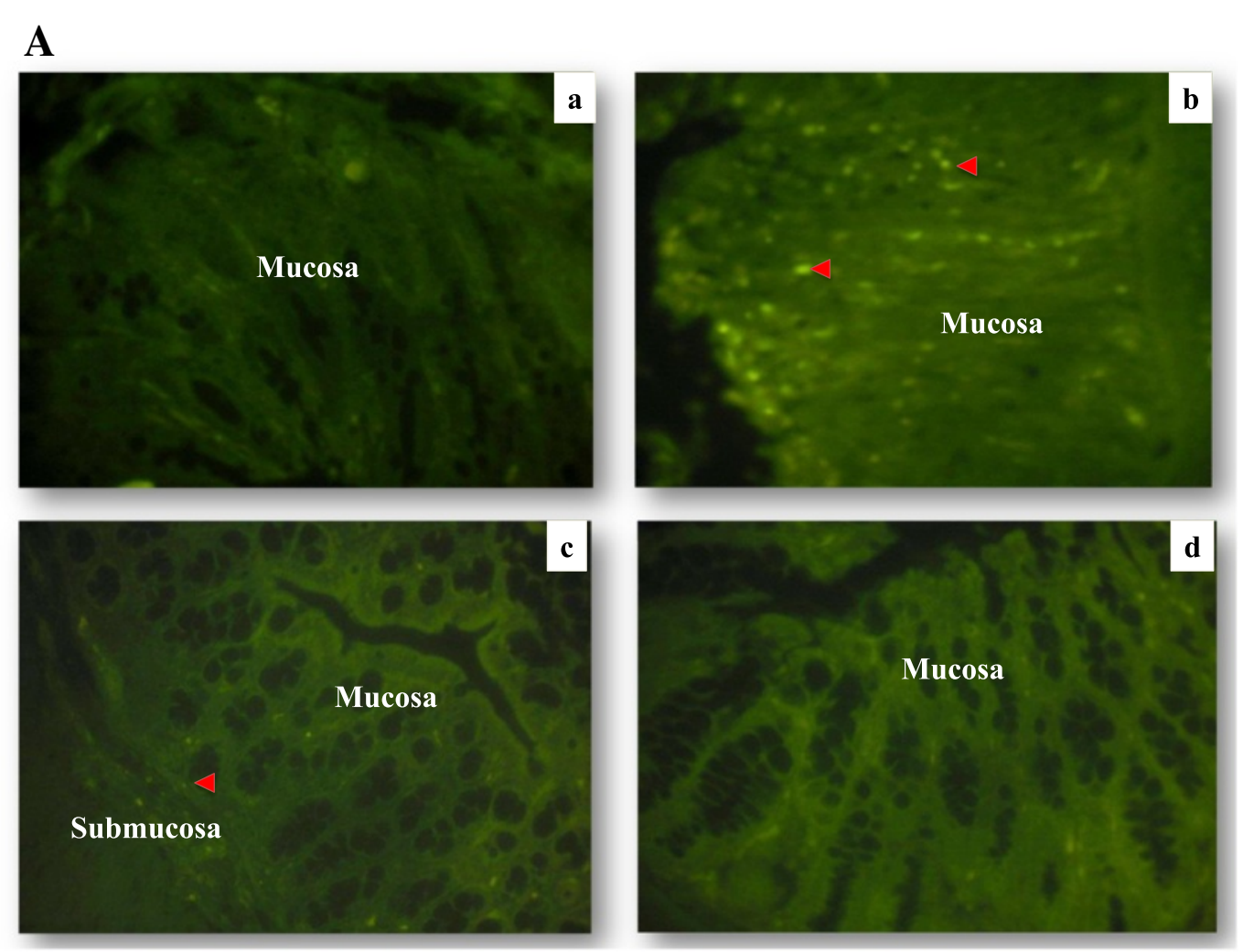

B

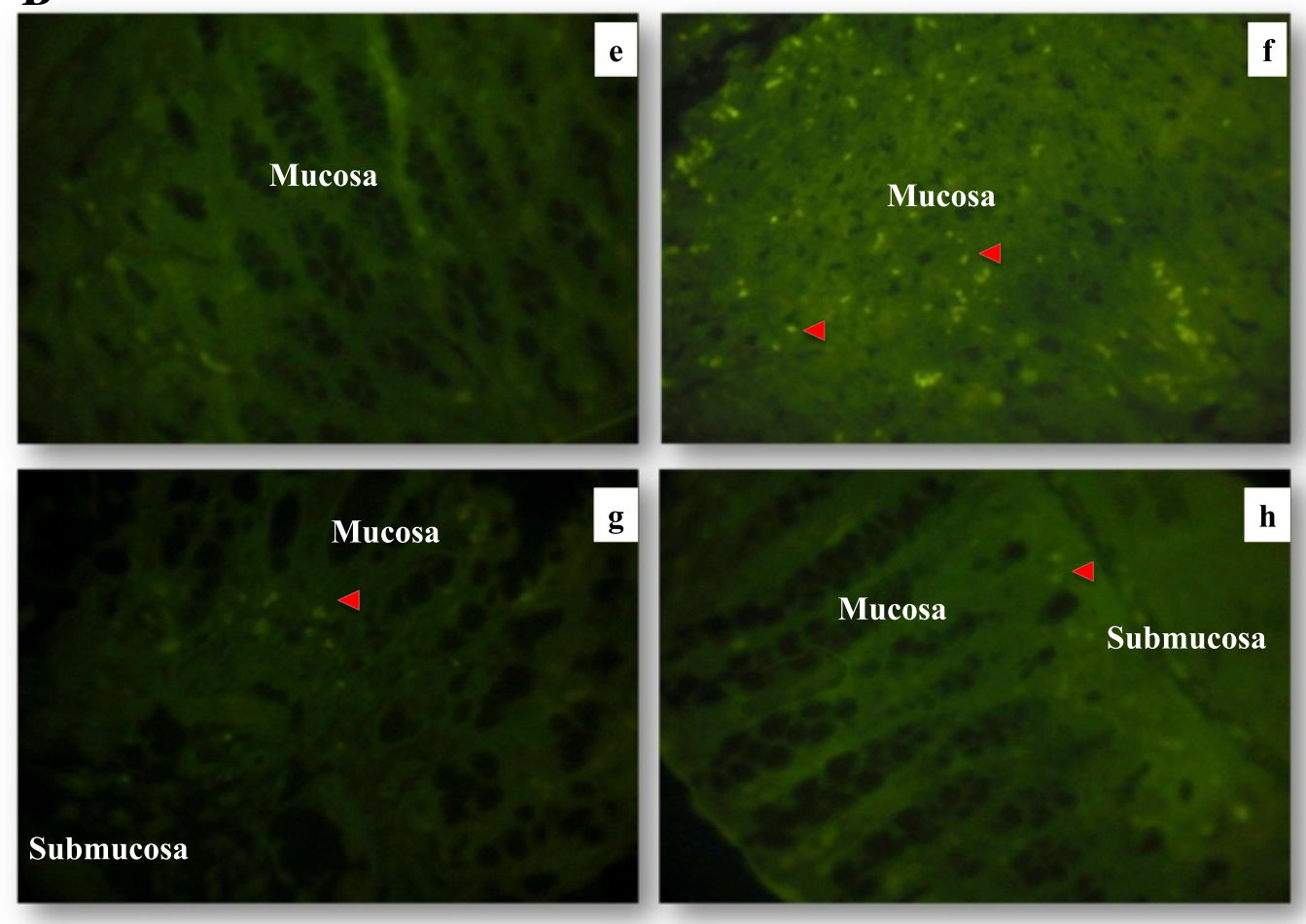

Figure 7 (See legend on next page.) 
(See figure on previous page.)

Figure 7 Representative images of immunofluorescence staining. Distal colon tissues from mice were stained with anti-iNOS (a-d) and anti p65 NF-KB subunit (e-h). Colonic tissue stained with anti-iNOS (a) CTRL group, (b) DSS group, (c) LL/DSS group, (d) LL group. Colonic tissue stained with anti-p65 subunit NF-KB (e) CTRL group, (f) DSS group, (g) LL/DSS group, (h) LL group. Red arrow indicates iNOS or NF-KB staining, all magnifications are $\times 40$.

Interestingly, the LL/DSS group showed a significant decrease in NO production, in both plasma and $\mathrm{pM} \Phi$ culture supernatants, compared with mice from the DSS group. Moreover, pretreatment of mice with hydatid LL induced a concomitant decrease of IFN- $\gamma$ and TNF- $\alpha$ levels in plasma and the attenuation of iNOS and NF- $\mathrm{kB}$ expression in the mucosa. Moreover, other studies have described an important immunomodulatory role for hydatid LL through the downregulation of NO production in mice in vivo and in vitro $[24,25]$.

However, administration of hydatid LL alone to BALB/C mice also induced an increase in plasma TNF- $\alpha$ and IFN- $\gamma$ levels, although without any significant effect on mouse health. This result is probably related to the heterogeneous mix of compounds present in the crude extract of the hydatid LL, which may induce immune responses in healthy mice. Hence, identification and purification of the bioactive molecule (s) should provide more potent and effective anti-inflammatory effects. Therefore, our future aim will be to characterize the bioactive molecules within the LL extracted from the cyst wall of E. granulosus.

The hydatid LL is a crucial element of the host-parasite interface. It represents an important barrier against immunological host responses [26,37]. To survive, the parasite impairs Th1 protective responses and induces Th2 and regulatory $\mathrm{T}$ cell (Treg) responses, which are then involved in the mechanism of the immune evasion strategy. This effect may be mediated by LL antigens [26,37]. Many reports suggest the ability of helminths to down-regulate the proinflammatory immune response via the induction of Tregs or the production of antiinflammatory cytokines, for example IL-10 and tumor growth factor $\beta$, which can regulate both Th1 and Th2 responses [38]. Thus, the decrease of $\mathrm{NO}$ and proinflammatory cytokine levels in plasma of pretreated mice LL is likely related to the immunomodulatory effect of the cystic extract. It appears that this effect may be mediated by the immunoregulatory action of IL-10, as this cytokine was highly increased during treatment with the cystic extract (Figure 6). It has been reported that IL-10 inhibits proinflammatory cytokine production, including IFN- $\gamma$, IL- $1 \beta$, TNF- $\alpha$ and IL-12, leading to the inhibition of iNOS expression. It has also been suggested that IL-10 may exert its regulatory functions through NF-kB inhibition [36].

\section{Conclusions}

Collectively, the results obtained are in favor of the hygiene hypothesis and suggest the existence of an immunoprotective effect mediated by helminths against colitis. In our model, this effect appears to be related to the action of larval structures during echinococcosis evolution. This beneficial effect of the hydatid LL could represent a promising therapeutic approach. However, further investigations are required to fully explore the safety aspects and elucidate the exact mechanism of action.

\section{Abbreviations}

ANDRS: National agency for research and health development; CTRL: Control; DAl: Disease Activity Index; DMEM: Dubbelco's modified Eagle medium; DSS: Dextran sulfate sodium; ELISA: Enzyme-linked immunosorbent assay; FITC: Fluorescein isothiocyante; H\&E: Hematoxylin and eosin;

IBD: Inflammatory bowel disease; IL: Interleukin; IFN- $\gamma$ : Interferon- $\gamma ;$ i. p.: Intraperitoneally; LL: Laminated layer; NO: Nitric oxide; iNOS: Inducible nitric oxide synthase; NF-KB: Nuclear factor kappa B; PBS: Phosphate-buffered saline; $P M \Phi$ : Peritoneal macrophages; SEM: Standard error of the mean; TNF-a: Tumor necrosis factor $a$.

\section{Competing interests}

The authors declare that they have no competing interests.

\section{Authors' contributions}

IS drafted the manuscript, performed all the experiments, contributed to the acquisition and interpretation of data. RT provided a technical contribution to the realization of the study and helpful discussion on the interpretation of data. HR provided a technical effort. MA made a technical and theoretical contribution to the realization of the study. LK and ML have provided a technical effort to the realization of the histological study. FN has been involved in revising the manuscript and provided an important intellectual contribution to the study. СTB supervised the research group, contributed to the execution of the study, wrote the ethics committee application and helped to draft the manuscript. All the experiments were performed in the University of Sciences and Technology Houari Boumediene USTHB, Laboratory of Cellular and Molecular Biology, Algiers, Algeria. All authors read and approved the final manuscript.

\section{Acknowledgments}

This work was supported by the national agency of scientific development and research in health (ANDRS). The authors would like to thank the patients who participated in this study.

We are grateful to Radhia Kraiba, Mohamed Kheddam and Katia Mangano for their help.

\section{Author details}

'Department of Biology, Laboratory of Cellular and Molecular Biology, University of Sciences and Technology Houari Boumediene USTHB, Algiers, Algeria. ${ }^{2}$ Department of Biomedical Sciences, University of Catania, Catania, Italy.

Received: 29 June 2014 Accepted: 24 February 2015

Published online: 17 March 2015

\section{References}

1. Sartor RB. Mechanisms of disease: pathogenesis of Crohn's disease and ulcerative colitis. Nat Clin Pract Gastroenterol Hepatol. 2006;3:390-407.

2. Xavier RJ, Podolsky DK. Unravelling the pathogenesis of inflammatory bowel disease. Nat. 2007:448:427-34.

3. Abraham C, Ruslan M. Interactions between the host innate immune system and microbes in inflammatory bowel disease. Gastroenterol. 2011;140:1729-37. doi:10.1053/j.gastro.2011.02.012. 
4. Dijkstra G, Moshage $H$, Van Dullemen HM, de Jager-Krikken A, Tiebosch AT, Kleibeuker $\mathrm{H}$, et al. Expression of nitric oxide synthases and formation of nitrotyrosine and reactive oxygen species in inflammatory bowel disease. J Pathol. 1998;86:416-21.

5. Kolios G, Brown Z, Robson RL, Robertson DA, Westwick J. Inducible nitric oxide synthase activity and expression in a human colonic epithelial cell line, HT-29. Br J Pharmacol. 1995;116:2866-72.

6. Kimura H, Miura S, Shigematsu T, Ohkubo N, Tsuzuki Y, Kurose I, et al. Increased nitric oxide production and inducible nitric oxide synthase activity in colonic mucosa of patients with active ulcerative colitis and Crohn's disease. Dig Dis Sci. 1997;42:1047-54.

7. Rafa H, Amri M, Saoula H, Belkhelfa M, Medjeber O, Boutaleb A, et al. Involvement of interferon- $\gamma$ in bowel disease pathogenesis by nitric oxide pathway: a study in algerian patients. J Interferon Cytokine Res. 2010;30:691-7.

8. Abdelouhab K, Rafa H, Toumi R, Bouaziz S, Medjeber O, Touil-Boukoffa C. Mucosal intestinal alteration in experimental colitis correlates with nitric oxide production by peritoneal macrophages: Effect of probiotics and prebiotics. Immunopharmacol Immunotoxicol. 2011;34:590-7. doi:10.3109/ 08923973.2011.641971.

9. Toumi R, Abdelouhab K, Rafa H, Soufli I, Raissi-Kerboua D, Djeraba Z, et al. Beneficial role of the probiotic mixture Ultrabiotique on maintaining the integrity of intestinal mucosal barrier in DSS-induced experimental colitis. Immunopharmacol Immunotoxicol. 2013;35:403-9. doi:10.3109/ 08923973.2013.790413.

10. Loftus Jr EV. Clinical epidemiology of inflammatory bowel disease: incidence, prevalence, and environmental influences. Gastroenterol. 2004;126:1504-17.

11. Weinstock JV, Elliott DE. Helminths and the IBD hygiene hypothesis. Inflamm Bowel Dis. 2009;15:128-33. doi:10.1002/ibd.20633.

12. Laclotte C, Oussalah A, Rey P, Bensenane M, Pluvinage N, Chevaux JB, et al Helminths and inflammatory bowel diseases. Gastroenterol Clin Biol. 2008;32:1064-74. doi: 10.1016/j.gcb.2008.04.030.

13. Sutton $T L$, Zhao A, Madden KB, Elfrey JE, Tuft BA, Sullivan CA, et al. Antiinflammatory mechanisms of enteric Heligmosomoides polygyrus infection against trinitrobenzene sulfonic acid-induced colitis in a murine model. Infect Immun. 2008;76:4772-82. doi:10.1128/IAI.00744-07.

14. Melon A, Wang A, Phan V, McKay DM. Infection with Hymenolepis diminuta is more effective than daily corticosteroids in blocking chemically induced colitis in mice. Biomed Biotechnol. 2009;2010:384523. doi:10.1155/2010/ 384523.

15. Khan WI, Blennerhasset PA, Varghese AK, Chowdhury SK, Omsted P, Deng Y, et al. Intestinal nematode infection ameliorates experimental colitis in mice. Infect Immun. 2002;70:5931-7.

16. Elliott DE, Setiawan T, Metwali A, Blum A, Urban JF, Weinstock JV Heligmosomoides polygyrus inhibits established colitis in IL-10-deficient mice. Eur J Immunol. 2004;34:2690-8.

17. Elliott DE, Li J, Blum A, Metwali A, Qadir K, Urban Jr JF, et al. Exposure to schistosome eggs protects mice from TNBS-induced colitis. Am J Physiol-Gastrointest Liver Physiol. 2003;284:385-91.

18. Smith P, Mangan NE, Walsh CM, Fallon RE, McKenzie AN, Van Rooijen N, et al. Infection with a helminth parasite prevents experimental colitis via a macrophage-mediated mechanism. J Immunol. 2007;178:4557-66.

19. Summers RW, Elliott DE, Urban Jr JF, Thompson RA, Weinstock JV. Trichuris suis therapy in Crohn's disease. Gut. 2005;54:87-90.

20. Summers RW, Elliott DE, Urban Jr JF, Thompson RA, Weinstock JV. Trichuris suis therapy for active ulcerative colitis: a randomized controlled trial. Gastroenterol. 2005;128:825-32.

21. Garg SK, Croft AM, Bager P. Helminth therapy (worms) for induction of remission in inflammatory bowel disease. Cochrane Database Syst Rev. 2014;20(1):CD009400. doi:10.1002/14651858.

22. Touil-boukoffa C, Sancëau J, Tayebi B, Wietzerbin J. Relationship among circulating interferon, tumor necrosis factor-a, and interleukin- 6 and serologic reaction against parasitic antigen in human hydatidosis. J Interferon Cytokine Res. 1997;17:211-7.

23. Diaz A, Casaravilla C, Irigoın F, Lin G, Previato J, Fernando F. Understanding the laminated layer of larval Echinococcus I: structure. Trends Parasitol. 2011;27:204-13. doi:10.1016/j.pt.2010.12.012.

24. Steers NJR, Rogan MT, Heath S. In-vitro susceptibility of hydatid cysts of Echinococcus granulosus to nitric oxide and the effect of the laminated layer on nitric oxide production. Parasite Immunol. 2001;23:411-7.
25. Andrade MA, Siles-Lucas M, Espinoza E, Arellano JLP, Gottstein B, Muro A Echinococcus multilocularis laminated-layer components and the E14t 14-3-3 recombinant protein decrease NO production by activated rat macrophages in vitro. Nitric Oxide. 2004;10:150-5.

26. Siracusano A, Delunardo F, Teggi A, Ortona E. Host-parasite relationship in cystic echinococcosis: an evolving story. Clin Dev Immunol. 2011;2012:639362. doi:10.1155/2012/639362.

27. Okayasu I, Hatakeyama S, Yamada M, Ohkusa T, Inagaki Y, Nakaya RA. Novel method in the induction of reliable experimental acute and chronic ulcerative colitis in mice. Gastroenterol. 1990;98:694-702.

28. Cooper HS, Murthy SN, Shah RS, Sedergran SJ. Clinicopathologic study of dextran sulfate sodium experimental murine colitis. Lab Invest. 1993;69:238-49.

29. Messaoudene D, Belguendouz H, Ahmedi ML, Benabdekader T, Otmani $F$, Terahi $M$, et al. Ex vivo effects of flavonoïds extracted from Artemisia herba alba on cytokines and nitric oxide production in Algerian patients with Adamantiades-Behçet's disease. J inflamm (Lond). 2011;21:35. doi:10.1186/1476-9255-8-35.

30. Siegmund B, Fantuzzi G, Rieder F, Gamboni-Robertson F, Lehr HA, Hartmann $\mathrm{G}$, et al. Neutralization of interleukin-18 reduces severity in murine colitis and intestinal IFN- $\gamma$ and TNF-a production. Am J Physiol Regul Integr Comp Physiol. 2001;281:1264-73.

31. Dieleman LA, Palmen MJ, Akol H, Bloemena E, Pena AS, Meuwissen SG, et al. Chronic experimental colitis induced by dextran sulphate sodium (DSS) is characterized by Th1 and Th2 cytokines. Clin Exp Immunol. 1998;114:385-91.

32. Obermeier F, Kojouharoff G, Hans W, Scholmerich J, Gross V, Falk W. Interferongamma (IFN- $\gamma$ )-and tumour necrosis factor (TNF)-induced nitric oxide as toxic effector molecule in chronic dextran sulphate sodium (DSS)-induced colitis in mice. Clin Exp Immunol. 1999;116:238-45.

33. Rachmilewitz D, Stamler JS, Bachwich D, Karmeli F, Ackerman Z, Podolsky DK. Enhanced colonic nitric oxide generation and nitric oxide synthase activity in ulcerative colitis and Crohn's disease. Gut. 1995;36:718-23.

34. Saura M, Zaragoza C, Clare B, McMillan A, Lowenstein CJ. Interaction of interferon regulatory factor- 1 and nuclear factor $\mathrm{kB}$ during activation of inducible nitric oxide synthase transcription. J Mol Biol. 1999;289:459-71.

35. Cheshire $J$, Baldwin AS. Synergistic activation of NF-kappaB by tumor necrosis factor alpha and gamma interferon via enhanced I kappaB alpha degradation and de novo I kappaBbeta degradation. Mol Cell Biol. 1997; 17:6746-54

36. Schottelius AJG, Baldwin Jr AS. A role for transcription factor NF-kB in intestinal inflammation. Int J Colorectal Dis. 1999:14:18-28.

37. Díaz A, Casaravilla C, Allen JE, Sim RB, Ferreira AM. Understanding the laminated layer of larval Echinococcus II: immunology. Trends Parasitol. 2011;27:264-73. doi:10.1016/j.pt.2011.01.008.

38. Maizels RM, Balic A, Gomez-Escobar N, Nair M, Taylor MD, Allen JE. Helminth parasites-masters of regulation. Immunol Rev. 2004;201:89-116.

\section{Submit your next manuscript to BioMed Central and take full advantage of:}

- Convenient online submission

- Thorough peer review

- No space constraints or color figure charges

- Immediate publication on acceptance

- Inclusion in PubMed, CAS, Scopus and Google Scholar

- Research which is freely available for redistribution 